\section{O feminismo negro de Patrícia Hill Collins: uma conversa sobre conhecimento, poder e resistência*}

Bruna Cristina Jaquetto Pereira (https://orcid.org/0000-0003-3213-8672), Instituto de Relações Internacionais, Universidade de Brasília (UnB), Brasília, Distrito Federal, Brasil'.

Joaze Bernardino-Costa (https://orcid.org/0000-0002-9937-893X), Departamento de Sociologia, Universidade de Brasília, Brasília, Distrito Federal, Brasil".

Em julho de 2019, a socióloga estadunidense Patricia Hill Collins veio ao Brasil pela primeira vez após a publicação de seu livro mais conhecido, Black feminist thought, em português, 19 anos após sua publicação original. Esta não foi a primeira visita de Collins ao Brasil, mas a importância dessa viagem em particular se deve ao maior alcance dos estudos produzidos por e sobre mulheres negras no país.

Pensamento feminista negro (2019) ocupa um lugar de destaque na expressiva produção acadêmica de mulheres negras brasileiras e estadunidenses, que vai ganhando espaço no universo intelectual brasileiro - ainda que de modo tímido e lento -, por dois motivos. O primeiro é o conteúdo das análises e as releituras que a obra propõe sobre a história e a sociedade estadunidense. O segundo, certamente mais valioso para quem não se interessa imediatamente pela situação dos Estados Unidos, são as sólidas contribuições do livro para uma forma de pensar, produzir teoria social e conhecimento que valoriza experiências e perspectivas de sujeitos que foram (e ainda estão) majoritariamente excluídos ou marginalizados pelas ciências sociais. Collins defende que centralizar tais vozes - particularmente, as vozes das mulheres negras - é um caminho para conferir visibilidade à natureza parcial de teorias sociais que se presumem universais, ao mesmo tempo em que permite a emergência de lentes inovadoras para olhar e analisar a realidade.

Como a obra de outras intelectuais negras, a produção de Collins defende abertamente a associação entre conhecimento e justiça social, reformulando noções tradicionais de objetividade, poder e autoridade na produção acadêmica. Que perguntas não têm sido feitas? Quais pontos de vista não têm sido considerados?
Recebido: 28.04.21 Aprovado: 21.09 .21

\footnotetext{
* A entrevista foi realizada em inglês e posteriormente editada pela entrevistada. A tradução para o português foi realizada por Bruna Cristina Jaquetto Pereira, com revisão de Joaze BernardinoCosta.

I. Bruna Cristina Jaquetto Pereira, doutora em sociologia pela Universidade de Brasília (UnB), é professora voluntária do Departamento de Relações Internacionais na Universidade de Brasília. <brunacjpereira@ gmail.com>.

II. Joaze BernardinoCosta é professor do Departamento de Sociologia da Universidade de Brasília. <joazebernardino@ gmail.com>
} 
Quais histórias ainda não foram contadas? Essas e outras questões presentes no livro certamente merecem ampla reflexão no âmbito das universidades brasileiras. Na ocasião de sua visita ao país, conversamos com Collins sobre aspectos ora mais amplos ora mais específicos de sua obra, seu modo de produzir conhecimento e suas estratégias para navegar o espaço acadêmico. Esperamos que a entrevista possa tanto instigar o público brasileiro a ler e estudar Pensamento feminista negro quanto desvelar algo da visão dessa importante intelectual na atualidade.

Bruna Pereira (BP) - A meu ver, é importante que as pessoas entendam o contexto no qual você escreveu o livro Pensamento feminista negro. Sei que esta é uma proposta muito ampla, mas a ideia é fornecer uma ideia geral do que se passava naquele momento.

Patricia Hill Collins (PHC) - Pensamento feminista negro é um pequeno exemplo de um universo de trabalho intelectual nos Estados Unidos que refletiu décadas de ativismo negro. O movimento pelos direitos civis e o movimento Black Power foram movimentos sociais que atuaram a partir da década de 1950 até a década de 1970 e que integraram um movimento afro-americano mais amplo, intergeracional, contra o racismo antinegro/a. Historicamente, as mulheres negras foram participantes importantes de múltiplas formas de ação política, por exemplo, em protestos sociais, políticas eleitorais e na criação de organizações de base, comunitárias, bem como desempenharam papéis relevantes em movimentos sociais negros. Mulheres negras também adotaram perspectivas ideológicas ao longo do amplo espectro do pensamento político e social afro-americano. Embora mulheres negras ativistas e intelectuais tivessem sido essenciais para o sucesso dessa ampla luta negra por liberdade, o significado de suas ideias e ações permanecia em grande parte invisível. A emergência de um movimento autoidentificado de mulheres negras na década de 1970 e sua disposição para reivindicar termos como feminismo negro e mulherismo desafiaram essa invisibilidade histórica.

Minhas experiências de amadurecimento como jovem mulher negra tiveram por pano de fundo a emergência da voz coletiva das mulheres negras durante a década de 1960 e 1970. Como estudante de ensino médio e depois de graduação, eu não apenas pensava sobre o material sobre o qual eu escreveria anos depois em Pensamento feminista negro, eu o vivia. A crescente visibilidade conferida ao ativismo de mulheres negras, especialmente de seu foco em gênero e seu compromisso intrínseco com uma análise interseccional, refletia um entendimento mais profundo não apenas sobre racismo sistêmico, mas também sobre o significado da análise genderizada para a política de resistência. O feminismo negro não surgiu de um 
movimento feminista mais amplo promovido por mulheres brancas. Ao contrário, para mim, ele se originou no reconhecimento crescente da necessidade da análise de gênero dentro dos projetos ativistas negros. Não seria possível libertar as muIheres negras sem levar tanto raça quanto gênero em conta.

Durante esse período, a visibilidade da ficção, poesia, música, dança e dos ensaios políticos de autoria de mulheres negras teve especial influência tanto em minha vida cotidiana quanto em minhas sensibilidades intelectuais emergentes. Esse foi um momento de florescimento da literatura de mulheres afro-americanas, mas dois livros se destacaram para mim, por terem um grande impacto nas mulheres negras ao meu redor. O livro de Toni Morrison, The bluest eye (O olho mais azul), e o volume editado de Toni Cade Bambara, The black woman, foram publicados em 1970, ano em que terminei meu mestrado em educação na Universidade de Harvard e comecei meu trabalho como professora do ensino médio na escola comunitária St. Joseph. De modo significativo, ambos os livros alcançaram um amplo público porque falavam sobre os problemas que as mulheres negras enfrentavam em ambientes acadêmicos e comunitários. Inicialmente publicados como livros de bolso vendidos a baixo custo, eles foram escritos em uma linguagem acessível às mulheres negras e levantaram questões que eram importantes em nossas vidas. Como autora vencedora do Prêmio Pulitzer por Beloved (Amada), o trabalho subsequente de Morrison é bem conhecido. Mas o livro de ensaios de Toni Cade Bambara é igualmente inovador ao mostrar a variedade de vidas e perspectivas políticas de mulheres negras. Morrison escreveu uma ficção gloriosa; Bambara colocou as ideias de muitas mulheres negras em diálogo. The black woman foi o primeiro livro que li que estabeleceu um diálogo entre ideias de mulheres negras sobre as questões que mais nos preocupavam. Eu levava os livros ao meu trabalho como professora do ensino médio em uma escola da comunidade negra e comecei a traduzir suas ideias de maneira que fossem significativas para meus/minhas alunos/as. Eu não sabia na época, mas comecei a pesquisar o Pensamento feminista negro durante meus anos trabalhando com crianças e adolescentes negros/as no movimento das escolas comunitárias nos anos de 1970.

Na década de 1980, quando comecei a escrever Pensamento feminista negro, eu tinha seis anos de experiência no movimento de escolas comunitárias negras e quatro anos como diretora de um programa para negros/as em uma faculdade de artes liberais. Eu sabia muito mais sobre como as ideias das mulheres negras eram vistas pela academia, em relação ao meu idealismo dez anos antes. Não só havia poucas mulheres negras em meus 12 anos de escola pública e quatro anos de faculdade, como muito poucas pessoas negras foram incluídas nos currículos. Como a produ- 
ção acadêmica de mulheres negras e sobre mulheres negras havia sido ignorada ou suprimida da academia, o trabalho intelectual das mulheres negras dentro da política cultural complementou minha educação formal.

Esse foi o principal motivo pelo qual fui trabalhar em um Departamento de Estudos Negros. Tive a sorte de conseguir um emprego estável em um departamento de estudos afro-americanos de uma grande universidade pública, o que me permitiu explorar muitas das questões que mais preocupavam os/as afro-americanos/ as com quem trabalhei no movimento de escolas comunitárias, e que eu conhecia em virtude desses anos de trabalho. Meus argumentos em Pensamento feminista negro foram alimentados pelo florescimento do trabalho intelectual de mulheres negras que entendi como um presente intergeracional de Morrison, Bambara e uma longa lista de intelectuais negras que me propus a citar em meu livro. Comecei a tentar compreender os padrões de ativismo e ideias que me cercavam. Era minha responsabilidade manter a conversa fluindo. Isso não foi fácil, mesmo dentro dos departamentos e programas de estudos negros, porque as tentativas de eliminar a segregação no ensino superior encontravam dificuldades. Trabalhar no ensino superior, ainda mais em uma unidade desvalorizada dentro do ensino superior, proporcionou desafios contínuos à integridade do meu trabalho intelectual, bem como ao meu próprio ser enquanto professora negra. Para mim, estar na academia constituiu uma continuação do ativismo do movimento negro. É importante ressaltar que, em nível nacional, a década de 1980 marcou o início de uma reação política contra muitas conquistas dos movimentos sociais, o que culminou na década de 1990 no esvaziamento de instituições públicas de educação, saúde, transporte e habitação e no financiamento do encarceramento em massa. Proteger os estudos negros como entidade institucional, e não apenas como conceito, era vital em meio a esse cenário político. Escrever o Pensamento feminista negro dentro desse contexto específico, ou seja, integrando uma unidade acadêmica desvalorizada e subfinanciada, lidando com o fato de que o legado de movimentos sociais negros parecia relegado ao passado e aprofundando as sensibilidades em relação a gênero e feminismo na sociedade estadunidense, foi um processo que teve suas limitações, mas que também me proporcionou liberdade intelectual e política. Sinceramente, fui subestimada, ignorada e fiquei isolada. Usei esse espaço para escrever.

Descrevo minha carreira de 23 anos como docente de um Departamento de Estudos Negros como uma luta para tornar possíveis as condições de meu próprio trabalho. Essa não foi uma tarefa fácil: eu estava escrevendo o Pensamento feminista negro durante um período em que faculdades e universidades desvalorizavam o trabalho intelectual das mulheres negras. Não estávamos simplesmente dessegregando a universidade, mas também o currículo e a pesquisa. Como os estudos 
sobre mulheres negras, especialmente as pesquisas em ciências sociais, historicamente não eram realizados por mulheres afro-americanas, eles rotineiramente depreciavam nossas experiências. E, no entanto, estudantes e professoras negras que ajudaram a dessegregar campi historicamente brancos foram aconselhadas a não desenvolver trabalhos sobre raça e sobre mulheres negras, pois isso poderia prejudicar nossas carreiras. Eu simplesmente teria que ignorar muitos conhecimentos sobre as mulheres negras a fim de assimilar tal conselho. Por exemplo, nas pesquisas das ciências sociais, a imagem da má mãe negra como a causa do baixo rendimento escolar das crianças negras e a aparente falta de vontade dos homens negros em sustentar suas famílias foram explicações importantes para a pobreza negra. Esse foi o período em que as mulheres negras eram estereotipadas como "mães do bem-estar" (welfare mothers), vivendo injustamente da generosidade do Estado, ou prostitutas sexualmente promíscuas, ou mães que deveriam ser gratas pelas esmolas dadas por seus empregadores/as brancos/as. A pesquisa sobre políticas públicas foi uniformemente negativa ao estigmatizar as mulheres negras e culpá-las por seus problemas sociais, além de retratá-las como um problema social para o próprio Estado.

O contexto político do período em que escrevi Pensamento feminista negro forneceu um pano de fundo importante para o livro, mas o principal desafio era pensar como eu navegaria no contexto intelectual acadêmico para publicar meu trabalho. Olhando para trás, vejo que meus argumentos sobre epistemologia ou teoria do conhecimento ofereceram um desafio muito maior para a pesquisa existente sobre mulheres negras do que simplesmente o de corrigir o registro histórico. Enquanto realizava as pesquisas que embasaram o Pensamento feminista negro, com frequência encontrei materiais, grande parte deles de autoria de mulheres negras, que refutavam o conhecimento acadêmico prevalente sobre mulheres negras. Ao fazer perguntas diferentes daquelas utilizadas pelo discurso dominante e estar aberta a outras fontes de dados que iam além do conhecimento convencional, fui capaz de elaborar meus argumentos. Percebi que as mulheres negras tinham uma longa história de produção intelectual nos Estados Unidos, expressa de modos que iam muito além das fontes acadêmicas tradicionais. Infelizmente, esse conhecimento muitas vezes permaneceu desconhecido mesmo entre as mulheres negras e certamente foi excluído do registro público.

Tudo isso exigiu que eu esclarecesse a natureza do meu projeto para mim mesma. 0 que me propus a fazer foi difícil, e eu tinha que deixar claro por que estava fazendo isso. Eu não estava escrevendo um livro de memórias da minha própria vida nem uma monografia padrão de ciências sociais que exigia que eu me distanciasse de minha própria experiência como evidência de minha objetividade. Eu não pretendia 
alcançar as pessoas por meio da ficção (como Toni Morrison) ou organizar as mulheres negras em uma comunidade política (como Toni Cade Bambara). Eu não estava trabalhando com o poder da música na cultura popular (como Nina Simone) ou tentando promover o ativismo de base nas comunidades negras (como o Coletivo Combahee River). Em vez disso, eu queria examinar o pensamento feminista negro em um livro que permitisse às mulheres afro-americanas afirmar as realidades das vidas das mulheres negras em nossos próprios termos, mas que também legitimasse o trabalho intelectual das mulheres negras dentro dos termos acadêmicos. Eu não conseguia me imaginar escrevendo um livro sobre mulheres negras em que não pudéssemos reconhecer as verdades sobre nossas próprias vidas. Além disso, eu não queria escrever um livro teórico que as mulheres negras não pudessem ler, entender e usar. Para fazer isso, tive que negociar demandas institucionais e epistemológicas que poderiam desvalorizar meu próprio projeto, e os argumentos que eu apresentaria. Meu objetivo era sintetizar a produção intelectual de mulheres negras para mulheres negras e, igualmente importante, ter esse pensamento feminista negro como conhecimento teórico legitimado em espaços acadêmicos.

Olhando para trás, posso ver os desafios epistemológicos que enfrentei ao escrever Pensamento feminista negro. Eu estava escrevendo para dois públicos, o do mundo cotidiano das mulheres negras e o mundo dos "guardiões" da Academia, que se esforçam para que não haja mudanças nos padrões tradicionais de produção de conhecimento. Em outras palavras, tive que descobrir uma maneira de escrever meu livro para mulheres negras em um formato que fosse reconhecido como produção acadêmica legítima. Tive de fazer algo bastante sofisticado, o que significava que precisava ter muita clareza sobre o que queria dizer e por quê. Além disso, como esses públicos tinham padrões diferentes, o que seria considerado uma evidência convincente para ambas as comunidades? E essas diferenças estão no cerne do desafio epistemológico de escrever esse livro. Agora, anos depois, posso descrever o que estava fazendo com maior precisão. No entanto, na época, eu estava apenas fazendo o melhor que podia. Mas houve muita experimentação. Eu apenas sentia que era a coisa certa a fazer.

Joaze Bernardino-Costa (JBC) - Me parece óbvio - e acho que a todos nós que lemos sua obra - a perspectiva dialógica está muito presente em seu modo de pensar, na elaboração de suas teorias e na escrita desse livro.

$\mathrm{PHC}-\mathrm{Sim}$.

JBC - Qual o impacto dessa perspectiva dialógica em relação aos/às seus/suas estudantes e com os movimentos sociais em seus escritos? 
PHC - Eu escrevi o Pensamento feminista negro em diálogo com meus/minhas alunos/as de graduação em minhas turmas sobre Mulheres negras contemporâneas, Sociologia da comunidade negra e Família negra. Como eu tinha uma carga horária pesada de ensino, usei meus cursos e conversas dentro e fora da sala de aula como forma de testar ideias. Como a maioria dos/as alunos/as dos cursos de estudos negros eram afro-americanos/as, isso mudou a atmosfera da sala de aula. Por eu dar aulas em uma instituição pública e por serem minoria, muitas vezes pela primeira vez, os/as alunos/as brancos/as não chegavam com a expectativa de que seriam privilegiados no espaço da sala de aula. Não havia necessidade de parar e filtrar e adequar tudo a um centro branco, real ou imaginário. Não estávamos preocupados com o olhar branco. Os/As alunos/as negros/as trouxeram experiências e ideias para nossas comunidades de sala de aula que iam de desafiadoras a comoventes. Eles tinham muito a me ensinar e aprendi a ouvi-los/as. Ao contrário de escrever para um público imaginário desconhecido, meu tempo com meus/minhas alunos/ as envolveu uma conversa cara a cara, onde aprendemos como consultar uns/umas aos/às outros/as. Eu adorava dar aulas na Universidade de Cincinnati, mas não estava trabalhando em uma escola onde tinha recursos infinitos e colegas perfeitos/ as. Eu não estava viajando para conferências e saindo com as grandes mulheres negras da época. As pessoas costumam presumir que eu conhecia Angela Davis, June Jordan, Audre Lorde, Flo Kennedy, Barbara Smith ou outras proeminentes ativistas intelectuais feministas negras da época, mas nada poderia estar mais longe da verdade. Eu era uma professora universitária comum, não efetiva, e ensinava a alunos/as comuns (embora inteligentes, importantes, corajosos/as e incríveis) em uma universidade pública.

O engajamento dialógico foi especialmente importante para a produção de Pensamento feminista negro. Para esse projeto, recrutei quatro alunas negras de minhas turmas e, quando o livro estava perto de ser concluído, pedi-lhes que lessem diferentes partes do manuscrito. Por meio de conversas face a face, individualmente e em pequenos grupos, minhas "revisoras", alunas de graduação, compartilharam comigo seus pensamentos sobre as várias ideias do livro. Eu estava menos interessada em observações do tipo que se faz em uma apresentação formal do que naquilo que elas escreveram nas margens do manuscrito enquanto o liam. Perguntei a elas: "Em que este livro as faz pensar? Estou interessada no que vocês pensam. Vocês poderiam me contar?". Porque acho que uma característica marcante do meu trabalho é a acessibilidade, ou seja, a capacidade de tornar ideias complexas acessíveis, e nisso a contribuição das minhas alunas foi inestimável. Elas identificaram partes do livro sobre as quais disseram: "Não sei do que você está falando aqui". Fiz uma nota mental para reescrever essas seções e deixá-las mais claras. Em outras partes do livro, os argumentos eram claros, mas o material em si 
simplesmente não dizia nada a elas. Eu tive que me perguntar o porquê. Eu estava especialmente interessada no que elas acharam do material que apresentei sobre a literatura de mulheres negras. Tentei colocar as ideias presentes na literatura das mulheres negras em diálogo com as experiências das minhas alunas. Incluí ideias presentes nas obras de intelectuais negras proeminentes para ver o que ressoava para elas. Em outros casos, incluí material sobre temáticas que foram negligenciadas. Por exemplo, tenho uma seção sobre avós negras, um grupo ignorado nas ciências sociais, mas muito proeminente na vida das mulheres afro-americanas. Lembro-me que uma jovem me disse: "Isso me lembra muito da minha vovó!". Era algo muito familiar para elas.

Usar uma perspectiva dialógica com grupos de fora de minhas salas de aula foi e continua sendo mais difícil, justamente porque tive que imaginar conversas antecipadas com leitores/as desconhecidos/as enquanto escrevia o livro. Os/As revisores/as acadêmicos/as anônimos/as constituíram um importante público imaginário para o diálogo. Seu trabalho era avaliar o livro por seus argumentos, sua erudição e suas citações. Enquanto escrevia, tive que manter o foco nas ideias das mulheres negras ao mesmo tempo em que imaginava como elas seriam recebidas pelos/as revisores/as (o tema da dupla consciência de W. E. B. Du Bois). Eu precisava agradar a esses/as "guardiões/ãs" institucionais e, se meus argumentos não fossem sólidos, arriscaria não ter o livro publicado. Uma maneira de equilibrar essa luta entre diálogos íntimos, cara a cara, realizado com meus/minhas próprios/as alunos/as, e os diálogos com leitores/as imaginários/as anônimos/as, sem rosto e ostensivamente objetivos, foi dialogar com públicos heterogêneos e especializados. Apresentei as ideias de Pensamento feminista negro para diversos públicos, por exemplo, grupos comunitários, em bibliotecas, para minhas colegas de cursos de graduação e pós-graduação, em conferências especializadas e conferências profissionais. Eu ainda trabalho dessa maneira - calibrando meus argumentos para as pessoas a quem estou falando e revisando meus argumentos no calor da apresentação ou pensando sobre eles depois dela.

Como Pensamento feminista negro foi meu primeiro livro, eu não sabia então o que sei agora. Apresentar o material do livro em espaços acadêmicos, enquanto eu escrevia diferentes capítulos, ofereceu diferentes tipos de conversas ou diálogos face a face que enriqueceram minha compreensão de meu próprio projeto. No decorrer da apresentação do material para diferentes públicos acadêmicos, obtive reações variadas em distintas disciplinas e campos de estudo, reações que refletiam o que as pessoas pensavam sobre a produção intelectual das mulheres negras, bem como sobre as mulheres negras quando elas entram na sala. Muitos/as acadêmicos/as pareciam bastante confortáveis levantando questões que eu duvido que teriam 
perguntado a um/a colega branco/a. Esse ceticismo sobre minha autoridade para analisar minhas próprias experiências surgiu não apenas em diálogos hostis, mas também nos lugares, em princípio, mais amigáveis. Por exemplo, lembro-me de minha primeira palestra na National Women's Studies Association, onde as participantes expressavam um forte interesse pelo feminismo negro. Mas elas não tinham certeza sobre o que ele era exatamente. Eu estava nervosa, mas a conversa fluiu bem. Mais tarde, porém, uma mulher veio até mim, disse-me que gostou da minha conversa e, com uma expressão perplexa, perguntou: "Quem te formou?" Essa era uma pergunta intrigante para mim, então perguntei o que ela queria dizer. Ela explicou: "Onde você estudou feminismo?" Essas eram perguntas inocentes da parte dela, mas falavam muito sobre as relações de poder da produção de conhecimento, especialmente as funções de controle da academia, mesmo dentro do feminismo. Aparentemente, eu não estava falando sobre o feminismo que ela tinha em mente. Olhei diretamente para ela e perguntei: "Você quer saber em qual programa de Estudos da mulher eu me formei?". Fiz uma pausa e continuei: "Não obtive minha formação na universidade. Este é meu próprio trabalho original". O silêncio que se seguiu falou por si mesmo. Ela entendeu o insulto implícito que havia em suas perguntas. Ela simplesmente não tinha sido exposta ao argumento de que o feminismo surge em ambientes diferentes do seu, no meu caso, dentro de lutas antirracistas em que mulheres negras desenvolveram análises de gênero que não carregavam o nome de feminismo.

A questão de como pensar seus públicos e quem são seus públicos, particularmente públicos múltiplos com diferentes histórias, pontos de vista e agendas políticas, foi essencial para a análise interseccional em Pensamento feminista negro. Usar uma metodologia dialógica requer estar preparada para o conflito. Diálogos são mais do que conversas amigáveis entre pessoas com opiniões diferentes. Eles podem sinalizar antagonismos profundamente enraizados e que se originam de interesses distintos. Aprendi isso quando apresentei o material sobre feminismo negro em uma universidade pública de uma grande área urbana que tinha um Departamento de Estudos Negros, um Programa de Estudos sobre as Mulheres e um Departamento de Sociologia, e que não se davam bem entre si. Os/As componentes de cada grupo eram previsíveis, no sentido de que forneciam pouco espaço para mulheres negras em "suas" áreas - os homens negros lideravam os estudos negros, as mulheres brancas dirigiam os Estudos sobre as mulheres e os homens brancos dominavam a sociologia. Minha análise do feminismo negro o posiciona simultaneamente em todas as três áreas, é crítica a cada uma delas, mas fica fora de todas as três. O feminismo negro desafiou o sexismo nas comunidades negras, e muitos acadêmicos negros resistiram a renunciar ao privilégio de gênero. Os homens negros viam as mulheres negras que abraçavam o feminismo negro como 
traidoras da raça: "Vocês (mulheres negras) deveriam cozinhar para nós, e nos dizer como somos maravilhosos, não nos criticar. Vocês não sabem como é difícil para os homens negros conseguirem ter isso na América branca?". As feministas brancas tinham uma agenda diferente. Elas queriam que minha palestra defendesse uma versão do feminismo ocidental que as deixassem solidamente no controle do termo "feminismo", bem como da agenda que ele gerou. Elas esperavam que nos comportássemos como uma torcida, e que eu me comportasse como a líder que enfrentaria seus colegas negros de quem, sinceramente, elas tinham medo. Fiel ao seu estilo, os sociólogos se esconderam atrás das proteções das ciências sociais ostensivamente objetivas: eles estavam lá apenas para tomar notas e não para tomar partido. O desafio era apresentar o pensamento feminista negro como forma de análise interseccional que ressoasse e desafiasse essas diferentes comunidades interpretativas.

Eu estava com medo quando entrei na sala de aula, mas confiei em minha habilidade de adaptar minha fala para públicos diversos, e que agora não eram mais imaginados, estavam sentados em grupos reconhecíveis em diferentes regiões da mesma sala. Minha estratégia de apresentação foi usar um caso que fosse menos ameaçador para cada grupo, mas a partir do qual eu também pudesse ser crítica e contundente em relação a cada grupo sem ser ofensiva. Fiz isso apresentando meu argumento principal: o feminismo negro moderno emergiu tanto como uma crítica às limitações dos movimentos dos direitos civis e do movimento Black Power e do feminismo branco, quanto do movimento antiguerra, que ilustrava como esses movimentos eram importantes, mas incompletos. Não confrontei meu público diretamente, mas sim critiquei os pressupostos que adotavam no enquadramento da década de 1960, um período político anterior, o qual cada um reivindicava de maneiras bastante diferentes. Ao desviar minha análise para uma era familiar, mas de material histórico desconhecido, demonstrei a parcialidade de cada uma de suas perspectivas e criei espaço para que a visão sintética do feminismo negro adentrasse as conversas de cada área.

Com essa estratégia, desarmei uma situação política altamente carregada, não dizendo o que se esperava que eu dissesse. Minha palestra criticou o patriarcado nas comunidades negras, o racismo no feminismo branco e a dependência excessiva da sociologia à classe como forma de evitar as questões espinhosas de raça e gênero. O público não sabia o que fazer comigo ou com as minhas ideias. Os homens negros vieram prontos para discutir comigo porque pensaram que já sabiam o que era o feminismo negro. "Você odeia os homens, não é?". Quando eles não conseguiram encontrar a feminista mítica que odeia homens em minha palestra, eles ficaram confusos. O feminismo negro parecia ser sobre trabalho, família e comunidade e 
coisas com as quais eles diziam se importar. As feministas queriam que eu culpasse os homens como um todo pelos pecados da sociedade. Quando evitei essa armadilha apontando minha solidariedade para com os homens negros, apontando as diferenças entre os homens que as prejudicavam, nossa sororidade compartilhada foi dissolvida. Os sociólogos esperavam que eu concedesse às questões de raça e gênero um status secundário e elevasse a classe como a resposta universal para os problemas das mulheres negras. Convenientemente, essa abordagem somente de classe apaga as particularidades das mulheres negras e pouco contribui para derrubar os interesses investidos dos privilegiados sociólogos brancos. Lembro-me de ter saído daquela conversa me sentindo incrivelmente aliviada e um tanto triunfante. $\mathrm{O}$ engajamento dialógico era desafiador, mas falar para públicos tão díspares ao mesmo tempo na mesma sala me levou a ser muito mais clara sobre minha análise do feminismo negro. Essa palestra foi uma das minhas melhores apresentações sobre interseccionalidade, sem que eu tenha sequer mencionado a palavra.

O engajamento dialógico não é fácil. Pensamento feminista negro, bem como minha pesquisa subsequente sobre interseccionalidade, reflete meu compromisso com essa metodologia como forma de desenvolver o trabalho intelectual. Carrego essas questões referentes ao público ao longo de meu trabalho intelectual, para cada palestra que faço ou livro que escrevo, implícita e explicitamente documento como o engajamento dialógico afeta o corpus de meu trabalho.

Em meu livro On intellectual activism (Collins, 2012), eu reúno palestras, ensaios e entrevistas que fornecem um ponto de entrada acessível para os principais temas de minha produção acadêmica. Estruturo minha produção acadêmica por meio de dois tipos principais de diálogo, a saber, falar a verdade frente ao poder (que é a linguagem especializada da academia, necessária para a legitimação) e falar a verdade às pessoas (minhas palestras públicas, atividades de ensino e entrevistas necessárias para que o público reconheça a autenticidade e a veracidade), como aspectos duais de engajamento dialógico. Minha abordagem do feminismo negro e da interseccionalidade reconhece as dificuldades do engajamento dialógico através das diferenças de poder. Quando se trata de analisar os cruzamentos entre conhecimento e poder, bem como as questões do público que moldaram meu trabalho, tive que considerar coisas que os/as teóricos/as sociais convencionais nunca tiveram que confrontar ao desenvolver suas contribuições. A política de engajamento dialógico na produção de trabalho intelectual, a partir das bases das hierarquias sociais de raça, gênero e classe, é uma delas.

BC - Enquanto conversávamos antes da entrevista, você mencionou algo muito interessante. Você disse que alguns estudiosos controlam a academia nos Estados 
Unidos e a forma como o Brasil é visto por lá. Gostaria que você abordasse duas questões. Primeiro, as mudanças na academia estadunidense em relação a como o Brasil é visto e, segundo, a importância das ações afirmativas para acesso ao ensino superior aqui no Brasil, que trouxe muitos/as estudantes negros/as para a universidade. Na sua opinião, como podemos abrir um novo diálogo a partir de uma perspectiva diferente sobre o Brasil?

PHC - Criar novos diálogos sobre o Brasil depende de se cultivar conversas entre intelectuais negras e negros que historicamente foram marginalizados/as, senão excluídos/as, de posições acadêmicas. Dois aspectos de sua pergunta informam esse processo, a saber, i. a questão de como a produção acadêmica sobre o Brasil nas instituições acadêmicas dos Estados Unidos reflete as perspectivas de acadêmicos/ as que não são necessariamente críticos/as da história racial do Brasil; e ii. fortalecer a formação de acadêmicos/as negros/as no Brasil por meio de políticas de ação afirmativa que visam expandir o número de estudantes e professores/as negros/as em instituições brasileiras. Embora distintas, essas duas coisas se informam uma à outra.

$\mathrm{Na}$ academia estadunidense, acadêmicos/as afro-americanos/as questionaram a política oficial de democracia racial do Brasil, sugerindo que o racismo colorblind e a democracia racial acobertam o racismo antinegro/a sistêmico vigente. Michael Hanchard, France Winddance Twine, Kia Lilly Caldwell e Kim D. Butler, entre outros/ as, abordaram diversos aspectos da vida dos/as negros/as brasileiros/as para desafiar a suposição de que a desigualdade racial não existe no Brasil (Butler, 1998; Caldwell, 2007; Hanchard, 1994; 2006; Twine, 1998). Essa primeira onda de estudos críticos sobre a vida dos/as negros/as no Brasil analisou os pressupostos da democracia racial e, ao fazê-lo, criticou implicitamente as estruturas interpretativas de acadêmicos/as estadunidenses que aderiam acriticamente a essa abordagem. Além disso, Kim Butler (uma historiadora) e Michael Hanchard (um cientista político) abordaram não apenas os contornos da identidade negra, mas também a resistência política negra. Tenho a impressão de que esses/as estudiosos/as trataram suas análises da experiência negra no Brasil com respeito, com o objetivo não de provar algumas teses preconcebidas sobre os/as negros/as, mas sim de criar espaço para o diálogo entre intelectuais negros/as brasileiros/as e estadunidenses sobre questões compartilhadas, embora vividas de forma diferente, tendo em vista o racismo sistêmico. Quando acadêmicos/as negros/as estadunidenses vêm ao Brasil e fazem pesquisas no Brasil, eles/as levantam diferentes questões e apresentam diferentes explicações que desafiam as estruturas existentes. Uma vez que eles/as produzem em inglês, seus trabalhos foram especialmente importantes para mim, que estava atenta às suas publicações. Sou uma das muitas acadêmicas/os negras/ os nos Estados Unidos que questiona a existência da democracia racial no Brasil. 
O impacto do trabalho dos/as acadêmicos/as negros/as estadunidenses no avanço de argumentos alternativos sobre a desigualdade racial no Brasil não passou despercebido pelos acadêmicos/as tradicionais. Refutar os paradigmas dominantes gera repercussões. Em um artigo de 1999 intitulado "On the cunning of imperialist reason", publicado na revista Theory, Culture and Society, Pierre Bourdieu e Loïc Wacquant acusaram intelectuais estadunidenses de se engajarem na "razão imperialista" por meio de esforços acadêmicos e institucionais para impor um paradigma norte-americano às relações raciais da sociedade brasileira e à produção acadêmica. Seus argumentos geraram um debate animado, que motivou uma sequência de muitos artigos que questionavam o argumento da razão imperialista. A tempestade de respostas a tal artigo é uma leitura fascinante que ilustra as tensões dentro da academia a respeito de quem controla o discurso do Norte Global sobre o Brasil. Por exemplo, em um artigo de 2003 intitulado "Acts of misrecognition: transnational black politics, anti-imperialism, and the ethnocentrisms of Pierre Bourdieu and Loïc Wacquant", Hanchard oferece um argumento contundente que refuta as afirmações dos autores. Há dois elementos aqui: a preocupação com os/as "mensageiros/as" (neste caso, estudiosos/as negros/as que trabalham com brasileiros/as em pesquisas antirracistas), e a preocupação com a própria mensagem, a saber, as afirmações de Hanchard de que o movimento negro visava desenvolver um ponto de vista autodefinido sobre o racismo antinegro/a no Brasil.

Podemos e devemos examinar em que pontos os/as estudiosos/as negros/as estadunidenses acertaram e em que pontos erraram em seus estudos sobre o Brasil, mas essa não é a questão principal. A reação negativa teve como alvo não apenas a substância da produção acadêmica no Brasil, mas também questionou implicitamente a crescente visibilidade dos/as acadêmicos/as afro-americanos/as na produção acadêmica estadunidense sobre o Brasil. E essa visibilidade, por sua vez, sinalizou um crescente mal-estar entre os/as acadêmicos/as brancos/as dentro da academia dos Estados Unidos em relação à crescente visibilidade de Latinx, indígenas, imigrantes e outros/as alunos/as e professores/as não brancos/as que se tornaram visíveis e que tratavam de questões relativas ao colonialismo, racismo, sexismo e homofobia. Esse artigo sobre a "razão imperialista" foi especialmente irônico. Quando penso em exemplos de imposição de abordagens por acadêmicos/ as ocidentais ao Brasil, a outros países da América Latina, à África e à Austrália, por exemplo, Michael Hanchard e outros/as estudiosos/as negros/as não são aqueles/ as que me vêm à mente. A aparente defesa dos/as intelectuais brasileiros/as por Pierre Bourdieu é especialmente significativa, dado o fato de que se poderia tomar sua produção acadêmica como sendo igualmente imperialista. Seu posicionamento exemplifica como muitos/as intelectuais ocidentais impõem seus entendimentos de raça e racismo em projetos pretensamente decoloniais. Bourdieu não é es- 
pecialista em Brasil, tampouco negro. Para mim, esse episódio foi bastante irônico, dada a resposta de Bourdieu a Frantz Fanon, à luta de libertação na Argélia nos anos 1950 e à produção acadêmica sobre raça (Collins, 2019: 77-80).

A segunda parte da sua pergunta diz respeito a como os/as negros/as no Brasil podem desenvolver e controlar a narrativa sobre suas próprias experiências. As políticas de ação afirmativa do Brasil, quando combinadas com iniciativas semelhantes de expansão do sistema universitário, são projetadas para criar mais oportunidades educacionais para os/as cidadãos/ãs brasileiros/as excluídos/as, a maioria dos/as quais são negros/as e/ou pobres. O resultado seria aumentar o número de alunos/ as e professores/as negros/as dentro da academia, com implicações importantes para o trabalho que ali se desenvolve. Há muito tempo existem intelectuais negros/ as brasileiros/as que desenvolvem análises sobre o racismo antinegro/a, com implicações importantes para a práxis política. O problema não é de falta de talento dos/ as negros/as brasileiros/as. Ao contrário, o problema tem sido a falta de oportunidade juntamente com a impossibilidade de alcançar posições de autoridade como professores/as, administradores/as, pesquisadores/as, editores/as de periódicos e editores/as-chefes em editoras. As ações afirmativas são projetadas para remediar os padrões de exclusão do passado, não apenas por razões cosméticas, mas para trazer novas pessoas e ideias para a academia.

A trajetória das políticas de ação afirmativa nas faculdades e universidades estadunidenses serve como advertência para as iniciativas brasileiras. Nos Estados Unidos, as ações afirmativas tiveram início com esforços formais para identificar a discriminação institucional, seguidos pelo empenho para identificar e recrutar alunos/ as e professores/as para as oportunidades recém-abertas. Os/As negros/as pressionaram por esses recursos legais e programas institucionais; remediar o racismo sistêmico estava inicialmente no centro das iniciativas de ação afirmativa. Este não é mais o caso. As ações afirmativas agora fazem referência a uma constelação de abordagens adotadas desde meados da década de 1960, que recrutou alunos/ as, professores/as, funcionários/as e administradores/as para a academia estadunidense não necessariamente com o objetivo de enfrentar o racismo, o sexismo e outros sistemas sociais injustos. Ao invés disso, as ações afirmativas, reformuladas pela linguagem da diversidade, da equidade e da inclusão, buscam promover a diversidade distanciada do intento de remediar a injustiça social. A ideologia da colorblindness anda de mãos dadas com o intuito de enfraquecer o mandato de justiça social das iniciativas de ação afirmativa. A política de ações afirmativas nos Estados Unidos tem sido reduzida aos esforços de mudança institucional em favor de agendas de diversidade cosmética (Collins, 2016: 179-188). 
Ao longo do tempo, estudantes e professores/as pobres e da classe trabalhadora foram substituídos por categorias aparentemente mais inclusivas, como pessoas não brancas que podem acomodar a diferença e a diversidade sem prejudicar as dinâmicas acadêmicas costumeiras. Alunos/as e professores/as com laços fracos com movimentos sociais que travaram duras lutas históricas, por exemplo, imigrantes negros/as estrangeiros/as ou afro-americanos/as ricos/as e de classe média, costumam ser mais atraentes para universidades que buscam diversidade cosmética em detrimento da igualdade. A diluição das ações afirmativas por meio do recrutamento de estudantes e acadêmicos/as negros/as mais palatáveis continuou a moldar o trabalho intelectual, pelo menos até o momento da emergência do movimento Black lives matter, em 2015, e do aparecimento das consequências da eleição presidencial de 2016 nos Estados Unidos. Esses eventos mudaram o clima político dentro das faculdades e universidades, e os efeitos dessas mudanças sobre as ações afirmativas ainda estão por ser vistos.

As ações afirmativas nos Estados Unidos servem de alerta ao Brasil, mas as ações afirmativas no Brasil não precisam seguir o roteiro estadunidense. Parece-me que o Brasil está em processo de construção de uma comunidade de jovens acadêmicos/as negros/as brasileiros/as que potencialmente podem se juntar às fileiras daqueles/as poucos/as acadêmicos/as negros/as seniores cujo trabalho dentro da academia abraça um mandato de justiça social. Tive a sorte de visitar o Brasil várias vezes, e a cada viagem fico impressionada não só com o volume e qualidade dos trabalhos de intelectuais negros/as brasileiros/as publicados em português, mas também pelo comprometimento de meus/minhas novos/as colegas com essa empreitada. Minha estante em Cincinnati tem um número crescente de livros que exploram a consciência política negra a partir da perspectiva de intelectuais negros/ as brasileiros/as, muitos/as dos/as quais são mulheres negras. Alguns exemplos: Letramentos de reexistência: poesia, grafite, música, dança: hip hop, de Ana Lúcia Silva Souza (2012); O movimento negro educador: saberes construídos nas lutas por emancipação, de Nilma Lino Gomes (2017), e Quem tem medo do feminismo negro?, de Djamila Ribeiro (2018) ilustram a diversidade de vozes negras brasileiras que agora estão sobre a mesa da produção intelectual.

Políticas de ação afirmativa podem ter aberto portas para essa geração de intelectuais negros/as enérgicos/as e entusiasmados/as. Mais oportunidades significam que mais alunos/as e professores/as negros/as estão avançando, e esses números contribuem para novos e estimulantes trabalhos. Infelizmente, essas tendências podem não durar em face da resistência do atual governo brasileiro contra a educação para jovens pobres e/ou negros/as. Mas os/as jovens resistem. O movimento 
de ocupação das escolas por estudantes do ensino médio em 2015-2016 contra cortes no orçamento para a educação pública cresceu, refletindo-se em muitos campi universitários e universidades brasileiras. Sem uma educação de qualidade para os/as alunos/as do ensino médio, as ações afirmativas para alunos/as de graduação perderão força. E isso, por sua vez, conforma o futuro corpo docente. Temos que esperar para ver como essas políticas governamentais e a resistência a elas funcionarão. Por enquanto, como uma estudiosa afro-americana dos Estados Unidos, meus encontros com a comunidade intelectual brasileira que assume uma postura crítica em relação ao racismo, tanto na academia quanto na práxis, são uma lufada de ar fresco. A análise crítica que vejo nos/as intelectuais negros/as brasileiros/as não é importada do exterior, mas sim original, nacional.

BP - No prefácio à primeira edição em inglês de Pensamento feminista negro, você fala sobre a experiência de ser "a primeira", "uma das poucas" ou "a única" pessoa negra, da classe trabalhadora e/ou a única mulher na escola, em determinadas comunidades e em certos ambientes de trabalho. Você descreveu tais situações como dolorosas e ressaltou que elas resultam em agressões diárias. Quais conselhos você daria para mulheres e homens negros que vivem hoje situações semelhantes?

PHC - Adotar a sabedoria de meus pais e sua visão de mundo, decorrentes de suas experiências prévias, foi essencial para que superasse os obstáculos. Em resumo, meus pais acreditaram em mim. Meu pai e minha mãe me deram o seguinte conseIho: "Não leve a discriminação para o lado pessoal. Não há absolutamente nada de errado com você. Mas há coisas que são nitidamente falhas em nossa sociedade". Minha primeira linha de defesa foi afirmar meu valor como ser humano. "Quando as oportunidades aparecem, você tem que estar pronta para aproveitá-las. Mas elas podem não aparecer para você. De toda forma, você tem que estar preparada". Ora, essa é uma mensagem sobre a discriminação institucional que pode ser traduzida como: "Você tem o poder de se preparar para o que a espera. Uma oportunidade pode aparecer e desaparecer. Se nenhuma porta se abrir, você mesmo terá que criá-la". Meus pais me mostraram como me proteger do que hoje chamamos de microagressões e como pensar estrategicamente e criar meu próprio caminho. Com ele e ela, aprendi que não bastava analisar a discriminação racial, que ambos vivenciaram ao longo da vida, mas que eu também precisava usar minha inteligência para analisar as estratégias de enfrentamento a situações injustas. A sociologia foi útil para mim porque forneceu um importante conjunto de ferramentas analíticas para me ajudar a traçar meu próprio caminho. Fui a primeira pessoa de minha família a concluir um curso do ensino superior. Combinar a visão de mundo de meus pais com meu treinamento sociológico me preparou para entrar, persistir e me destacar em ambientes frequentemente hostis. 
Alguém tem que ser o/a primeiro/a da fila, com a esperança de que outros/as o/a sigam. É difícil ser a primeira porque, quando você é a primeira, sua família, amigos/as e membros da comunidade muitas vezes não conseguem entender os desafios que você enfrenta. A pessoa que vem primeiro é um agente de mudança, tanto no novo ambiente educacional e profissional quanto para as pessoas de sua casa. Aconselho outros/as que são os/as primeiros/as a olharem para as relações de poder que estruturam as oportunidades e obstáculos. Os entrecruzamentos das relações de poder baseadas em raça, classe e gênero moldaram minha trajetória nas instituições de ensino como estudante e como professora. Aqueles/ as de nós que são os/as primeiros/as na academia sempre tentamos nos provar pelos padrões de vários/as "guardiões/ãs" do modelo tradicional de produção de conhecimento. Mas pergunte a si mesmo/a: quem pode defender melhor os seus interesses? As pessoas que colocam obstáculos institucionais em seu caminho estão tentando derrubá-lo/a - elas não o/a amam. Racismo, sexismo, exploração de classe e homofobia muitas vezes significam que eles/as não conseguem nem mesmo vê-lo/la como pessoa, muito menos importar-se com você ou amá-lo/la. Eles desvalorizam suas ideias, seu intelecto e seu corpo; sua presença é uma fonte de ruptura no que era confortável e normal para eles/as. Ser o/a primeiro/a traz feridas que, se tivermos sorte, se transformam em cicatrizes de batalha. Eu certamente experimento racismo, sexismo e sistemas semelhantes de opressão como indivíduo, mas sempre me foi útil saber que meu valor como pessoa não pode ser medido pelos padrões estabelecidos por sistemas sociais injustos. Embora me afete como indivíduo, a discriminação institucional é direcionada a meu grupo. Ser a primeira da fila me ensinou a não personalizar nem capitular ao racismo, ao sexismo, à exploração de classe e a sistemas semelhantes de opressão, a menos que eu esteja em perigo. Quando é a minha própria alma que está em jogo, me proteger vem em primeiro lugar.

JBC - Em um dos prefácios a Pensamento feminista negro, você afirma que "Para capturar as interconexões de raça, gênero e classe social na vida das mulheres negras e seus efeitos no pensamento feminista negro, rejeitei explicitamente fundamentar minha análise em uma tradição teórica única". Isso sugere que nenhuma teoria em isolado é capaz de dar conta disso. Por que não, se elas supostamente deveriam ser universais e representar as experiências sociais de qualquer pessoa?

PHC - Acho que a maneira ocidental de fazer a teoria social torna impossível criar qualquer coisa que se aproxime do universal. A meu ver, essa aspiração pela teoria universal significa ignorar detalhes de uma dada teoria enquanto se concentra em outras. A teoria universal só pode ser universal por meio da exclusão e da abstração. Tais teorias formulam as questões e interpretações que se tornam prevalecen- 
tes e nos encorajam a explorar apenas as teorias já existentes em busca de insights sobre questões que levantamos ou a ajustar nossas próprias análises a estruturas que já são, de alguma forma, preconcebidas. Para que tenham sentido, as teorias sociais ocidentais exigem a exclusão de grandes conjuntos de experiências e de perspectivas alternativas. Isso não torna necessariamente essas teorias tendenciosas, embora esse possa certamente ser o caso, mas sim, parciais. A maioria dos trabalhos teóricos que li e que afirmam ser universais são tipicamente muito particulares. Ler dessa forma não significa que sejam teorias ruins. Significa apenas que elas são lentes diferentes de análise dos fenômenos sociais específicos e das questões que mais me interessam. Acho que a questão é aprender a ler todas as teorias sociais de outra maneira. Eu leio teorias pretensamente universais levando em conta tanto o que está presente quanto o que está faltando. Esse tipo de leitura é especialmente importante para teorizar sobre as experiências de grupos subordinados. De que maneira adicionar o que está faltando muda o que é considerado verdade?

Mais importante ainda, as questões que trago para as teorias mudam a forma como as leio. Mas muitas vezes essas questões vêm de fora daquilo que a teoria social aparentemente universal considera importante. Por exemplo, há muito tempo estou interessada em teorizar a resistência, e meu trabalho sobre mulheres negras tem se dedicado a essa tarefa. Esse esforço para trazer uma lente ou estrutura diferente para a teoria social me levou a procurar explicações alternativas e frequentemente opostas para o mesmo conjunto de fenômenos sociais. Quando se trata das realidades materiais de mulheres negras, a busca da teoria social ocidental para entender a ordem social só serve para explicar por que as mulheres negras deveriam permanecer em seus lugares. Mesmo assim, as mulheres negras há muito têm desenvolvido um ponto de vista distinto sobre essa mesma realidade material, que catalisa outras questões, explicações e ações sociais distintas.

Além disso, ler de maneira diferente tais teorias não significa deter-se aos limites de suas experiências próprias e definhar estacionado/a em sua própria zona de conforto. Esse tem sido o problema das teorias sociais dominantes - engajar-se em conversas particularistas entre si que simplesmente reciclam velhas ideias, que só podem parecer universais porque são repetidas com muita frequência. Em contraste, meu trabalho com mulheres negras me encorajou a ir além do conforto conquistado a duras penas por agora ter o pensamento feminista negro. Vir ao Brasil me permitiu me esforçar mais e me obrigar a ver as semelhanças e diferenças de fazer o mesmo trabalho em diferentes contextos nacionais. Minhas viagens para a Nova Zelândia, Canadá e Austrália trazem um novo significado ao termo "mulheres negras", de maneiras que mostram semelhanças e diferenças entre ne- 
gros/as e indígenas. Embora frequentemente controverso, o engajamento dialógico como metodologia pode produzir teorias sociais universais capazes de acomodar experiências heterogêneas quanto à raça, gênero, classe, sexualidade, nação, etnia, habilidade e geração.

BP - Sua análise de raça, gênero e classe social - tanto sobre opressão quanto sobre resistência - enfatiza a relação entre conhecimento e poder. Nesse sentido, algumas das principais contribuições encontradas em Pensamento feminista negro é o conceito de "imagens de controle". No livro, você afirma que as imagens de controle incorporam o pensamento binário e a objetificação, e que naturalizam - e assim, justificam e perpetuam - injustiças e opressões. Quais mecanismos de dominação você buscou destacar com esse conceito? Seria mais a questão da representação ou, como você mencionou em outra ocasião, a questão dos estereótipos? Ou os preconceitos inconscientes? Ou como racismo, classismo e sexismo institucional?

PHC - As pessoas costumam confundir estereótipos e imagens de controle, usando-os de forma intercambiável em análises de desigualdade social. Mas esses dois constructos têm implicações diferentes sobre como as ideias são importantes nas relações hierárquicas de poder. Para mim, estereótipos são crenças errôneas sobre um determinado grupo que facilitam visões preconceituosas sobre ele. Esse é o caso, por exemplo, de pessoas brancas que acreditam que os/as negros/as são menos inteligentes ou mais inclinados/as ao crime, ou homens que acreditam que as mulheres são menos racionais e mais emocionais, ou pessoas ricas que acreditam que seu privilégio imerecido Ihes dá o direito de comprar qualquer coisa. Crenças errôneas como essas encorajam a expressão da discriminação contra negros/as, mulheres e outros grupos discriminados. O problema dos estereótipos reside na política de mudança social que eles engendram. A solução para o dano causado pelos estereótipos consiste em despojar as pessoas das visões estereotipadas. Nos Estados Unidos, temos uma abundância de iniciativas de diversidade bem-intencionadas em campi universitários que visam reeducar os/as alunos/as sobre grupos subalternizados, fornecendo-lhes informações mais precisas sobre eles. Certamente, ter mais informações é melhor do que ter menos, mas a suposição de que o racismo e o sexismo irão acabar quando as pessoas brancas e os homens estiverem mais bem informados/as simplesmente não se provou correta. Dessa forma, o termo "estereótipo" tem certas implicações políticas, a saber, que certos indivíduos causam racismo, sexismo e outros tipos de discriminação porque têm crenças errôneas, e que a mudança social ocorre ao se concentrar na mudança de mentalidade desses indivíduos preconceituosos. 
As "imagens de controle" estão mais atentas às relações de poder, e isso significa observar como as ideias moldam não apenas as relações interpessoais entre os indivíduos, mas também as relações sociais estruturadas entre grupos sociais. Vejo minha pesquisa sobre imagens de controle como parte de meu projeto mais amplo de teorizar a resistência às relações de poder que se entrecruzam. Ele exigiu que eu pensasse teoricamente sobre o poder, não apenas usando-o para descrever os tipos de relações de poder - como, por exemplo, racismo, sexismo, etc. -, mas também para examinar os entendimentos que se tem sobre o poder. No início de minha carreira, vi a necessidade de utilizar um vocabulário acessível para especificar como o poder se organiza e opera. Apresentei uma proposta que esboça o modo como os domínios de poder estrutural, disciplinar, cultural e interpessoal constituem aspectos interconectados das relações de poder. Os domínios da estrutura de poder são muito versáteis. Em minha produção acadêmica, apliquei essa abordagem a diferentes aspectos da dominação, escrevendo artigos que tratam da desigualdade social dentro de um domínio ou, alternativamente, examinando como as relações através dos e/ou entre os domínios se informam mutuamente. Fiz isso em vários de meus livros e artigos, e particularmente em Black feminist thought (Collins, 2000), Another kind of public education (Collins, 2009) e Intersectionality (Collins; bilge, 2020). Essa é uma das vantagens de se ter uma longa carreira: a possibilidade de tratar de diferentes aspectos de um único tópico ou tema importante.

Como o domínio cultural do poder concentra-se na dinâmica das representações, crenças e comportamentos, o constructo das imagens de controle está fortemente associado a ele, tanto no que se refere à sustentação da dominação política quanto na resistência a ela. Ainda assim, as imagens de controle conectam todos os domínios de poder. A ideia de imagens de controle tem servido como pedra de toque para investigar diferentes organizações e a própria dinâmica das relações de poder. Como baseei meu trabalho nas ideias e experiências de mulheres afro-americanas, as imagens de controle referidas a esse grupo forneceram um importante ponto de partida - mas não um ponto final - para analisar a importância das imagens de controle. Pensamento feminista negro é parte desse projeto de pensar como as ideias não apenas oprimem, mas também podem fortalecer. A estrutura dos domínios de poder é uma ferramenta analítica para pensar de forma mais robusta sobre como as imagens "controlam" o comportamento de indivíduos e grupos em vários domínios de poder. Este é um tópico muito amplo para eu explicar aqui, mas várias questões se sobressaem.

Para trazer uma primeira questão, as imagens de controle são eficazes porque seu conteúdo não é uniformemente negativo. As imagens de controle podem ser positi- 
vas, situação na qual elas se tornam mais difíceis de serem vistas como tal, especialmente quando referidas a pessoas privilegiadas. Imagens de controle positivas podem exercer controle com a mesma força que as negativas. Analisar o mundo social por meio de uma abordagem a estereótipos coloca alguns grupos em situação de privilégio porque eles escaparam das implicações negativas dos estereótipos. Isso se aplica aos estereótipos sobre pessoas brancas, heterossexuais, ricas e homens ocidentais porque as características que Ihes são atribuídas são positivas, além de serem a referência para o ideal social. Em contraste, analisar o mundo social a partir das imagens de controle indica que as imagens de controle positivas sobre a masculinidade branca podem prender os homens brancos em uma masculinidade tóxica, por meio da qual eles confundem dominação com masculinidade. Nesse sentido, eles são controlados pela visão positiva da masculinidade branca e visam impor essa visão de sua superioridade ao usar essa imagem para controlar todos/ as os/as outros/as.

Outra questão que se pode levantar é como as imagens de controle operam em relações de poder mais amplas, particularmente importante para os indivíduos de grupos subordinados. Como elas controlam as pessoas? Usar a expressão "imagens de controle", como termo que se refere ao poder, cria espaço para se pensar a agência de algumas maneiras interessantes. Porque, uma vez que você nota que um conjunto específico de imagens de controle ganha significado apenas no contexto mais amplo de uma constelação de imagens de controle interconectadas, você pode compreender melhor como as pessoas desenham essas imagens dentro de sistemas de dominação. Imagens de mulheres negras, por exemplo, não estão isoladas. Estão relacionadas a imagens de mulheres brancas, a imagens de Latinxs, a imagens de homens, às de pessoas LGBTQ. De muitas maneiras, as imagens controladoras de qualquer sociedade, do Brasil e dos Estados Unidos, por exemplo, são um conjunto de textos que organizam ideias interseccionais daquela sociedade e que, por estarmos inseridos/as em nossas respectivas sociedades, usamos para atribuir sentido às realidades em que nos encontramos. E essas são realidades atravessadas pelo poder.

Ainda outra questão é que, como as imagens de controle estão interconectadas, elas fornecem uma janela para se observar as relações de poder interseccionais. Raça, classe, gênero, sexualidade, idade, habilidade e cidadania conformam as relações hierárquicas de poder entre múltiplos grupos sociais. A forma como respondemos às imagens de controle que são aplicadas a nós mesmos/as e aos/às outros/as é crucial para o modo como as relações de poder que se entrecruzam são organizadas e operadas. Não é suficiente entender quais imagens se aplicam a você. Em vez disso, a solução para essa desigualdade não é apenas mais informações ou algum 
tipo de treinamento ou sensibilidade. A solução está em desenvolver uma análise para ver as maneiras como as imagens de controle moldam as próprias relações de poder.

Em se tratando de mudança social, as imagens de controle oferecem muito mais espaço para se desafiar as hierarquias sociais, e trazem desafios muito maiores para aqueles/as de nós que pretendem construir comunidades democráticas inclusivas. Os estereótipos encorajam a tolerância para com os/as outros/as, uma forma sutil de interagir em uma sociedade democrática. Em contraste, por exigirem o exame das relações de poder entre as pessoas como um processo contínuo para o qual cada um/a de nós contribui, as imagens de controle constituem uma forma mais ampla de encarar as desigualdades interseccionais. A agência é central aqui. Acho que é uma epifania para uma garota negra de 14 anos perceber que a imagem controladora de uma prostituta se aplica a ela, e que muito provavelmente foi tão naturalizada e normalizada que ela pode não ter percebido. E é uma epifania para um garoto branco de 14 anos considerar como seu privilégio heterossexual masculino pode predispô-lo a ver as garotas de sua escola, e especialmente as garotas negras, como prostitutas. A mesma imagem pode controlar grupos diferentes de maneiras diferentes. Esse reconhecimento pode catalisar momentos de compreensão que são pontos de partida para análise e ação. Eles fornecem um texto para novos tipos de conversas, que vão além do "pare de pensar essas coisas", "essas coisas são erradas". Como as imagens de controle fornecem scripts sociais de como todos/as nós devemos nos comportar, resistir a elas envolve não apenas entender o conteúdo das imagens, mas também como elas funcionam na manutenção das relações de poder.

Em meus primeiros trabalhos, pouco falei sobre como os mecanismos específicos de controle das imagens se articulam com as relações de poder. Mais recentemente, avancei nas minhas reflexões sobre como as imagens de controle exercem controle através dos domínios do poder, principalmente em virtude das muitas perguntas que recebo sobre as imagens de controle. Elas parecem propiciar um ponto de entrada para todos os tipos de interesses no terreno desafiador da dinâmica do conhecimento e das relações de poder. Recentemente, publiquei um pequeno artigo sobre as imagens de controle em um volume editado intitulado Fifty concepts for a critical phenomenology (Weiss, Murphy \& Salamon, 2020), em que reflito sobre as questões levantadas por sua pergunta. Embora eu tenha voltado repetidamente à elaboração das imagens de controle, aquele pequeno artigo esboça algumas ideias importantes. Se você me fizer essa pergunta de novo nos próximos anos, espero ter uma resposta mais clara. Quando se trata da importância das ideias nas relações de poder entrecruzadas e de como as imagens de controle como formas específicas de 
representação se encaixam nesse processo, esse ponto da minha produção ainda está em desenvolvimento.

JBC - Minha pergunta não é exatamente sobre Pensamento feminista negro, mas sobre sua carreira e sua opinião sobre o que está acontecendo no mundo, principalmente nos Estados Unidos, com Donald Trump, e no Brasil, com Jair Bolsonaro. Como o seu trabalho pode nos ajudar a interpretar o que está acontecendo aqui e nos Estados Unidos, e como pode nos oferecer algumas ferramentas para lutar contra isso?

PHC - Refletir sobre os desafios deste momento histórico e como podemos responder a eles exige uma visão de longo prazo sobre como as relações de poder são organizadas e operam ao longo do tempo. A dominação pode parecer permanente, mas as formas que ela assume nunca o são. As pessoas que estão no poder sempre têm vantagens inerentes que basicamente colocam o baralho a seu favor. No curto prazo, as pessoas que estão no poder vencem e suas vitórias são mais visíveis durante certos períodos do que em outros. Mas é importante ressaltar que as pessoas que estão na base nem sempre perdem e, no longo prazo, podem estar ganhando. Quando se trata de iniciativas de justiça social, ter uma visão de longo prazo é crucial. Algumas mudanças sociais são inteiramente possíveis amanhã, enquanto outras podem exigir um compromisso de várias gerações. O mundo social atual nunca está acabado - não é um roteiro "para sempre", ou então nunca teríamos mudanças sociais. Não acredito em teorias que argumentam que o racismo, o sexismo e a exploração de classe configuram nossas sociedades em hierarquias permanentes de vencedores/as e perdedores/as de tal modo que não faz sentido resistir à injustiça social. Também rejeito as narrativas ocidentais de mudança evolucionária linear, segundo as quais forças lentas invisíveis transformam gradualmente a desigualdade social. Ao contrário, acredito que as desigualdades sociais em qualquer momento e em qualquer ambiente refletem uma tensão criativa nas relações de poder de opressão e resistência que estão sempre presentes ao mesmo tempo. Onde há opressão, haverá resistência. Por outro lado, quando a resistência oferece benefícios tangíveis para os/as que estão na base, a reação negativa é inevitável. Pode parecer que aqueles/as que estão no topo têm todas as cartas, mas isso nunca acontece.

Meu trabalho sobre feminismo negro me convenceu de que as pessoas encontram maneiras de resistir, independentemente da profundidade da dominação histórica ou da magnitude da reação negativa prevista contra os projetos de justiça social. Quando penso na resistência das mulheres negras, posso invocar imagens de muIheres negras poderosas, de braços dados, em lutas heroicas que levam à vitória. 
Mas isso, para mim, é apenas uma das formas de resistência que, como nossa discussão anterior sobre a universalidade da teoria social, se mascara como uma forma de resistência aparentemente universal. As mulheres negras, no contexto dos Estados Unidos, fazem parte de um grupo de pessoas a quem foi negada a humanidade porque éramos vistas não como pessoas, mas como propriedade móvel. As mulheres negras criaram sua política em um contexto de terrorismo - porque para mim, a escravidão e suas consequências são terrorismo. Grande parte da resistência das mulheres negras esteve oculta porque se dava em um contexto muito perigoso, ou então foi erroneamente reconhecida como alguma outra coisa. $\mathrm{Na}$ verdade, a resistência das mulheres negras residia na recusa de aceitar voluntariamente o seu lugar de subordinação, mesmo quando forçadas a se submeterem. Também envolveu o plantio de sementes para as gerações futuras, deixando vestígios para que as encontrássemos tão logo nós puséssemos procurá-las. Mesmo quando as mulheres negras não podiam falar a verdade aos/às poderosos/as, elas falavam a verdade umas às outras, especialmente aos/às seus/suas filhos/as. Isso nos permite ver que a resistência é de longo prazo, requer compromisso e é profundamente criativa.

Ter essa visão de longo prazo da resistência política também significa expandir nossa noção de consciência e ação política para além da política formal. Não nos dedicamos o suficiente a estudar a resistência para além da ação política que visa diretamente as instituições do Estado como foco da mudança. É possível que nossa abordagem da resistência política precise mudar durante os períodos de conflito racial sancionados pelo Estado como, por exemplo, no caso das administrações Trump e Bolsonaro, bem como em relação a contextos sociais mais amplos de opressão que não podem ser fixados pela ação do Estado em isolado. No pensamento feminista negro, enxergo a vida cotidiana das mulheres negras como um local de subordinação e resistência. Sabemos muito sobre como as instituições de subordinação podem ser poderosas. Mas, por uma variedade de razões, sabemos muito menos sobre a resistência cotidiana nesse longo espectro da transformação política. A metáfora de apertar uma bexiga explica a natureza do longo prazo tanto da opressão quanto da resistência. A dominação absoluta e a tirania inevitavelmente estouram o balão e o sistema não pode sobreviver. Em vez disso, é preciso desenvolver maneiras de exercer pressão contínua sobre as pessoas para sujeitá-las. Mas aqui, aqueles/as que estão por baixo têm uma vantagem, pois sabemos que nossas ações são interpretações, enquanto os/as poderosos/as que consomem imagens controladoras sobre nós têm muito mais probabilidade de se convencer de que suas interpretações são verdadeiras. Há uma diferença entre ser a mammy e interpretar a mammy. Sempre que uma potência dominante pensa que acabou com a resistência, que não há como resistir, parece que as pessoas encontraram 
uma nova maneira de fazê-lo. Às vezes, isso ocorre por meio de atos de microrresistência ou, muitas vezes, apenas mantendo seus/suas filhos/as vivos/as e, ao fazer isso, mantendo viva a esperança. Mas a resistência também pode ocorrer por meio do conhecimento que se recusa a ser subordinado, catalisando assim uma predisposição para a consciência oposicionista, quando não ela própria.

[Nota adicional da autora] Que diferença faz o tempo entre a ocasião inicial dessa entrevista em Brasília em julho de 2019 e agora. Enquanto edito o texto da entrevista, Donald Trump e Jair Bolsonaro estão ambos na Presidência, mas a situação política no Brasil e nos Estados Unidos mudou dramaticamente. Estou encerrando esta entrevista em junho de 2020, no meio de um ano de grande importância global. A chegada do Covid-19 constituiu uma pandemia global que iluminou as disparidades mundiais nas mortes de Covid, onde negros/as, pessoas não brancas e/ou pessoas pobres morrem em taxas muito mais elevadas do que brancos/as. O fechamento sem precedentes da economia global, que deixou milhões de pessoas desempregadas e levou à insegurança alimentar, mostrou a profundidade da desigualdade social global. Significativamente, estou enviando esta entrevista no meio do testemunho de várias semanas de protesto social global contra o racismo sistêmico. Assistir às filmagens da morte de George Floyd por um policial que se ajoelhou em seu pescoço até a sua morte foi demais para os/as afro-americanos/ as e para muitas pessoas que foram às ruas em nome da decência. Nunca pensei que veria o dia em que brancos/as marchariam sob a bandeira do Black lives matter. A transmissão do assassinato de Floyd pela televisão foi um fósforo que acendeu a fogueira, um catalisador para uma série de ações sociais que pediam o desenraizamento de todos os vestígios de opressão racial. Isso é sem precedentes em minha vida e levará tempo para se ver o quão profundo é o compromisso com a mudança social e quais os efeitos que advirão dessa manifestação de apoio ao Black lives matter.

Quando realizamos esta entrevista em Brasília, nenhum desses eventos estava no horizonte. Quando esta entrevista for traduzida para o português, publicada e divulgada aos/às leitores/as, cada um/a de nós estará vivendo em um mundo diferente, que nenhum/a de nós pode prever hoje. Não há receitas ou fórmulas a seguir, mas sim estratégias que se apresentam se soubermos ler o mundo social não apenas por seus constrangimentos, mas também por suas possibilidades. O povo comum dos Estados Unidos e do Brasil merece uma liderança melhor do que a que teve no passado recente. Ter essa visão de longo prazo da resistência política significa ser estratégico/a e pragmático/a sobre os desafios das novas realidades políticas das estruturas políticas formais, mas, ao mesmo tempo, recusar-se a renunciar a ideais visionários do que ainda é possível. 


\section{Referências}

BUTLER, Kim D. Freedoms given, freedoms won: Afro-Brazilians in post-abolition Sao Paulo and Salvador. New Brunswick, NJ: Rutgers University Press, 1998.

CALDWELL, Kia Lilly. Negras in Brazil: re-envisioning black women, citizenship, and the politics of identity. New Brunswick, NJ: Rutgers University Press, 2007.

COLLINS, Patricia Hill. Pensamento feminista negro: conhecimento, consciência e a política do empoderamento. São Paulo: Boitempo Editorial, 2019 [1990].

- Intersectionality as critical social theory. Durham, NC: Duke University Press, 2019.

O que é um nome? Mulherismo, feminismo negro e além disso. Cadernos Pagu, n. 51, 2017. Disponível em: <https://www.scielo.br/pdf/cpa/n51/ 1809-4449-cpa-18094449201700510018.pdf>. Acesso em: 26 Abr. 2021.

. On Intellectual activism. Philadelphia, PA: Temple University Press, 2012.

. Another kind of public education: race, schools, the media and democratic possibilities. Boston, MA: Beacon Press, 2009.

Black feminist thought: knowledge, consciousness and the politics of empowerment. 2. ed. New York; London: Routledge, 2000 [1990].

COLLINS, Patricia Hill; BILGE, Sirma. Intersectionality. 2. ed. Cambridge, UK: Polity, 2020 [2016].

GOMES, Nilma Lino. O movimento negro educador: saberes construídos nas lutas por emancipação. Petrópolis, RJ: Vozes, 2017.

HANCHARD, Michael G. Party/politics: horizons in black political thought. New York: Oxford, 2006.

. Orpheus and power: the movimento negro of Rio de Janeiro and São Paulo, Brazil, 1945-1988. Princeton, NJ: Princeton University Press, 1994.

PASCHEL, Tianna S. Becoming black political subjects: movements and ethno-racial rights in Colombia and Brazil. Princeton, NJ; Oxford, UK: Princeton University Press, 2016.

RIBEIRO, Djamila. Quem tem medo do feminismo negro? São Paulo: Companhia das Letras, 2018. 
SOUZA, Ana Lúcia Silva. Letramentos da reexistência. Poesia, grafite, música, dança: hip hop. São Paulo: Parábola, 2012.

TWINE, France Winddance. Racism in a racial democracy: the maintenance of white supremacy in Brazil. New Brunswick, NJ: Rutgers University Press, 1998.

WEISS, Gail; MURPHY, Ann V.; SALAMON, Gayle (Orgs.). 50 concepts for a critical phenomenology. Evanston, IL: Northwestern University Press, 2020.

(c) (7) (9) 
